\title{
Editorial tribute to Elizabeth Bates
}

PING LI

University of Richmond

December 2004

The passing of Elizabeth Bates (Liz) has been a great loss to our field. Many colleagues have simply put it this way: the field will never be the same without Liz. Many others have written articles and monographs in honor of her contributions to psycholinguistics, cognitive science, and neuroscience (Karmiloff-Smith, 2004; Tomasello and Slobin, 2004; Hernandez, Li and MacWhinney, 2005; $\mathrm{Li}$, Tan and Tzeng, 2005; to name a few). Organizations such as ASHA and Society for Cognitive Development have also organized special symposia in honor of her contributions in the areas of speech, hearing, and developmental sciences. Here I pay tribute to Liz's significant contributions to research on bilingualism and her professional service to our journal. ${ }^{1}$

Liz had a genuine interest in languages, both as objects of scientific investigation and as ways of exploring life. As a fluent English-Italian bilingual, she developed sharp insights into the dynamic interactions of two or more languages. This insight led her to develop a general theory of first and second language acquisition based on principles of neural plasticity, competition, and transfer (see Hernandez et al., 2005 for a theoretical discussion). Her interest in multiple languages also led her to conduct the many cross-linguistic comparisons that formed the backbone of the Competition Model (Bates and MacWhinney, 1987). Testing the predictions of the Competition Model in more than a dozen languages, Liz realized that if the model was to serve as a true psycholinguistic model, it must provide mechanisms to explain linguistic representation and language processing in special populations, including both people who cannot speak even one language (aphasics) and people who speak more than one languages (bilinguals). ${ }^{2}$ Together with Brian MacWhinney, her foreign colleagues (e.g. Antonella Devescovi, Michèle Kail, Csaba Pleh, and others) and their many students (e.g. Arturo Hernandez, Kerry Kilborn, Hua Liu, and Janet McDonald), Liz succeeded in building a model that accounts for bilingual processing and second language acquisition as well as normal and disordered language processing across languages.

1 Dr. Bates had served on the Editorial Board of Bilingualism since the journal was founded and had reviewed a number of significant publications for the journal.

2 Dr. Bates never used the term 'special' to refer to the bilingual population, as she fully realized that bilingualism is the norm rather than the exception in our world today.
At UCSD's Center for Research in Language (CRL), Liz initiated several important research projects funded by $\mathrm{NIH}$, including the multilingual aphasia project and the project on bilingualism and aging. In the early 1990s, she invited François Grosjean, the founding editor of this journal, to CRL for discussion and exchange of ideas. When I started my postdoc research at CRL, Liz had become interested in how the contrasting features of Chinese and English might help to explain mixed language representations and the transfer of cues in language processing. In a study of Chinese-English bilinguals at different proficiency levels (Liu, Bates and Li, 1992), we found significant effects of forward transfer and backward transfer, and showed that these patterns of transfer depend on age of acquisition and have a nonlinear developmental trajectory. These data also supported Liz's belief that language performance in $\mathrm{L} 2$ hinges on the competition between the two languages - L1 and L2 can gain different strengths (wax and wane) over the lifespan of learning, and either L1 or L2 may become the dominant language, in different contexts, as a function of the interactions between experience, motivation, acculturation, and age of acquisition.

Liz was a foremost spokesperson for the interactive dynamic perspective on language learning and language processing. Her emphasis on interaction and dynamics extended to every aspect of her personality and lifestyle. Everyone who had the opportunity to discuss projects and ideas with Liz was delighted with the originality and non-linearity of her rapidly flowing ideas. Her passionate interest in a uniquely broad range of cognitive and developmental issues continues to inspire her students and colleagues to pursue a dynamic account of the interactions between language, brain, and behavior. It is sad that we will have to conduct these further adventures without Liz's presence in the field, but it is gratifying to see that her passion for languages and bilingualism is being carried on by so many researchers, in so many countries, and in so many languages. ${ }^{3}$

3 A memorial for Dr. Bates was held in La Jolla on February 15, 2004. The family requests that in lieu of flowers, contributions be sent to the Elizabeth Bates Graduate Research Fund, c/o Center for Research in Language - MC 0526; University of California, San Diego, La Jolla, CA 92093-0526, USA. In keeping with Dr. Bates's deep commitment to supporting students, this fund will be used to assist graduate students in their research, emphasizing the many areas in which she made pioneering contributions. 


\section{References}

Bates, E. \& MacWhinney, B. (1987). Competition, variation, and language learning. In B. MacWhinney (ed.), Mechanisms of language acquisition, pp. 157-193. Hillsdale, NJ: Erlbaum.

Hernandez, A., Li, P. \& MacWhinney, B. (2005). The emergence of competing modules in bilingualism. Trends in Cognitive Sciences.

Karmiloff-Smith, A. (2004). Editorial obituary: Elizabeth Bates (1947-2003). Language and Cognitive Processes, 19, 177179.
Li, P., Tan, L. \& Tzeng, O. J. L. (2005). Epilogue: A tribute to Elizabeth Bates. In P. Li, L.-H. Tan, E. Bates \& O. Tzeng (eds.), Handbook of East Asia psycholinguistics, vol. 1: Chinese. Cambridge: Cambridge University Press.

Liu, H., Bates, E. \& Li, P. (1992). Sentence interpretation in bilingual speakers of English and Chinese. Applied Psycholinguistics, 13, 451-484.

Tomasello, M. \& Slobin, D. I. (2004). Beyond naturenurture: Essays in honor of Elizabeth Bates. Mahwah, NJ: Erlbaum. 